\title{
Quality of life, emotion regulation, and heart rate variability in individuals with intellectual disabilities and concomitant impaired vision
}

\author{
Adrian Meule $^{1 *}$, Katharina Fath ${ }^{2+}$, Ruben GL Real ${ }^{1}$, Stefan Sütterlin ${ }^{3,4}$, Claus Vögele $^{3,4}$ and Andrea Kübler ${ }^{1,5}$
}

\author{
* Correspondence: \\ adrian.meule@uni-wuerzburg.de \\ ${ }^{\dagger}$ Equal contributors \\ 'Department of Psychology I, \\ Institute of Psychology, University of \\ Wuerzburg, Marcusstr. 9-11, 97070 \\ Wuerzburg, Germany \\ Full list of author information is \\ available at the end of the article
}

\begin{abstract}
Background: Positive associations have been found between quality of life, emotion regulation strategies, and heart rate variability (HRV) in people without intellectual disabilities. However, emotion regulation and HRV have rarely been investigated in people with intellectual disabilities. Assessment of subjectively reported quality of life and emotion regulation strategies in this population is even more difficult when participants are also visually impaired.

Methods: Subjective and objective quality of life, emotion regulation strategies, and HRV at rest were measured in a sample of people with intellectual disabilities and concomitant impaired vision $(N=35)$. Heart rate was recorded during a 10 min resting period. For the assessment of quality of life and emotion regulation, custom made tactile versions of questionnaire-based instruments were used that enabled participants to grasp response categories.

Results: The combined use of reappraisal and suppression as emotion regulation strategies was associated with higher HRV and quality of life. HRV was associated with objective quality of life only. Emotion regulation strategies partially mediated the relationship between HRV and quality of life.

Conclusions: Results replicate findings about associations between quality of life, emotion regulation, and HRV and extend them to individuals with intellectual disabilities. Furthermore, this study demonstrated that quality of life and emotion regulation could be assessed in such populations even with concomitant impaired vision with modified tactile versions of established questionnaires. HRV may be used as a physiological index to evaluate physical and affective conditions in this population.

Keywords: Quality of life, Emotion regulation, Heart rate variability, Cardiac autonomic regulation, Intellectual disability, Impaired vision
\end{abstract}

\section{Background}

Quality of life refers to the general well-being of an individual. While most humans can provide information about this quite easily, the assessment of quality of life in people with intellectual disabilities can be challenging. Research in people without intellectual disabilities shows that specific emotion regulation strategies are differentially related to quality of life and to physiological indices. In this paper, we first outline the concept of quality of life and its assessment in people with intellectual disabilities. 
Research on different emotion regulation strategies and their relationships with quality of life is then discussed. Finally, associations between cardiac autonomic regulation and both emotion regulation and quality of life are presented and findings integrated to explore whether emotion regulation (assessed by both subjective and physiological indices) was associated with quality of life in an intellectually and visually impaired adult population.

\section{Quality of life}

In 2006, the Convention on the Rights of Persons with Disabilities stated that people with disabilities should receive wide-ranging habilitation and rehabilitation services to achieve the highest level of independence, inclusion, participation, and abilities in the fields of health, employment, society and education (United Nations 2006). Since the 1980s, quality of life has become an important measure within intellectual disability research to measure these goals (Cummins 1997).

According to Cummins et al. (1994), quality of life can be divided into an objective and a subjective dimension. The subjective dimension comprises two components: importance and satisfaction. On all three parts of quality of life, i.e. objective quality of life and importance of and satisfaction with subjective quality of life, seven domains are represented. These domains are material well-being, health, productivity, intimacy, safety, place in community and emotional well-being (Cummins et al. 1994). Assessing quality of life - particularly its subjective components - in people with intellectual disabilities is difficult (McVilly et al. 2008) and many measures lack good psychometric properties (Townsend-White et al. 2012). The Comprehensive Quality of Life Scale for people with intellectual disabilities (Com-QOL-ID, Cummins et al. 1997) is one of the few measures that meet criteria of good psychometric properties and theoretical background. The Com-QOL-ID is the only instrument that measures objective and subjective quality of life on different axes as recommended in the literature (Townsend-White et al. 2012). Furthermore, it is the only standardized and sufficiently validated quality of life measure for people with intellectual disabilities available in German (Krüger 1998).

\section{Emotion regulation}

"Emotion regulation refers to the process by which we influence what emotions we experience, when we do so, and how we experience and express them" (Gross 2002, p. 282). Two of the most often investigated emotion regulation strategies are cognitive reappraisal and expressive suppression (e.g. Webb et al. 2012). While cognitive reappraisal refers to a change of thoughts about a situation, expressive suppression implies the inhibition of emotional expression and behavior. Both strategies are differently associated with quality of life and psychopathology such that cognitive reappraisal has been found to be a rather adaptive emotion regulation strategy while suppression appears to be maladaptive. For example, infrequent use of emotional reappraisal strategies was associated with reduced quality of life in patients with multiple sclerosis in addition to the effects of disease severity (Phillips et al. 2009). In non-clinical samples, suppression was positively correlated with depressive symptoms and rumination while reappraisal was negatively related with rumination and neuroticism (Gross and John 2003; Abler and Kessler 2009). However, recent research has also emphasized that 
people have a repertoire of emotion regulation strategies that they use flexibly depending on circumstances (Bonanno et al. 2004). Furthermore, the use of adaptive emotion regulation strategies can compensate for the use of maladaptive strategies and, therefore, prevent psychopathology (Aldao and Nolen-Hoeksema 2012).

Research on emotion regulation in people with intellectual disabilities is rare (McClure et al. 2009). Wilson (1999) found that children with developmental delay apply less effective strategies of emotion regulation than children without developmental delay. Similarly, children with developmental delay had lower scores on the emotion regulation subscale of the Bayley Behavior Scales than those without developmental delay (Baker et al. 2002). Nevertheless, children with intellectual disabilities had no disadvantage in expressing or regulating their emotions compared to typically developing children in a study by Baurain and Nader-Grosbois (2012).

\section{Heart rate variability}

Heart rate variability (HRV) refers to the variation of heart beat intervals and is influenced by sympathetic and parasympathetic input to the sino-atrial node of the heart. Increased high-frequent parasympathetically (vagally) mediated modulations increase HRV while increased low-frequent sympathetic activation (sympathovagal imbalance) decreases HRV (Task Force of The European Society of Cardiology and The North American Society of Pacing and Electrophysiology 1996). Higher vagal-cardiac control or higher HRV reflects higher cardiovascular flexibility. This enables an organism to quickly adapt to changing environmental requirements. Moreover, the neurovisceral integration model provides a link between prefrontal and subcortical brain structures and the autonomic regulation of cardiac activity (Thayer and Lane 2000, 2009; Thayer et al., 2012). Because of those associations, HRV has also been proposed as an index for self-regulatory strength (e.g. Segerstrom and Solberg Nes 2007; Smith et al. 2011). In line with this, higher HRV is associated with more adaptive emotion regulation (Appelhans and Luecken 2006). For instance, adolescents who reappraised an anger-inducing situation had higher resting HRV than those who ruminated about their anger (Vögele et al. 2010). In a study by Aldao and Mennin (2012), healthy controls had higher HRV when instructed to implement adaptive emotion regulation strategies, e.g. reappraisal, during an emotion-eliciting film clip. Besides those studies that investigated emotion regulation strategies in a specific situation in the lab, it has also been found that the habitual use of more adaptive emotion regulation strategies, e.g. reappraisal, is associated with higher HRV (Geisler et al. 2010).

HRV has rarely been investigated in people with intellectual disabilities. First evidence suggests cardiac autonomic dysregulation in adolescents with mental retardation (Gorbunov 2004) or individuals with Down syndrome (Baynard et al. 2004). Most recently, it has been reported that adults with intellectual disabilities had lower HRV than adults without intellectual disabilities (Chang et al. 2012).

\section{Aims and hypotheses}

As noted above, both HRV and quality of life are associated with distinct emotion regulation strategies. It appears that the habitual use of reappraisal in particular is related to higher HRV and higher quality of life. Recently, it could be shown that HRV is also 
indirectly associated with subjective well-being. Geisler et al. (2010) studied the relationships between HRV, satisfaction with life, and the habitual use of executive emotion regulation strategies which included refocusing, reappraisal, planning, putting into perspective, and distraction. They found that more frequent use of executive emotion regulation strategies was associated with higher HRV and higher satisfaction with life. A direct association between HRV and satisfaction with life, however, could not be found. Instead, they found an indirect relationship such that the impact of HRV on satisfaction with life was mediated by the use of executive emotion regulation strategies.

In the current study, we assessed quality of life, emotion regulation strategies, and HRV in a sample of individuals with intellectual disabilities and concomitant impaired vision. Due to their visual impairment, these individuals only receive restricted information through their visual modality and, therefore, the visual presentation of selfreport measures is extremely difficult. Receiving information via the tactile or haptic modality is particularly important in those people (McLinden 2012). To accommodate the difficulties with visual perception and need for tactile information, we modified response categories of questionnaire-based instruments to three-dimensional objects.

We hypothesized positive relationships between all three variables. Specifically, as HRV has been (indirectly) associated with higher quality of life (e.g. Geisler et al. 2010) and with the habitual and situation-specific use of adaptive emotion regulation strategies, e.g. reappraisal (e.g. Geisler et al. 2010; Vögele et al. 2010), we expected that HRV would be (at least indirectly) positively related to quality of life and to the habitual use of reappraisal. Based on the fact that the use of adaptive emotion regulation strategies, e.g. reappraisal, is related to a higher quality of life (e.g. Geisler et al. 2010) and that adaptive emotion regulation strategies are particularly effective in reducing psychopathology when maladaptive strategies are also present (e.g. Aldao and NolenHoeksema 2012), we expected that reappraisal would be positively correlated with quality of life, particularly in combination with high suppression. Subsequently, we tested whether the use of specific emotion regulation strategies mediated the relationship between HRV and quality of life.

\section{Methods}

\section{Ethical approvals}

This research was undertaken with the understanding and written consent of each participant and, where required, their legal representatives. The study protocol followed the Declaration of Helsinki (World Medical Association 2008). It was also independently reviewed and approved by the ethical board of the medical faculty at the University of Würzburg, Germany.

\section{Participants}

Participants $(N=35)$ were a convenience sample of residents of an institution for individuals with intellectual disabilities and concomitant visual impairment in Würzburg, Germany. Approximately half of the sample $(54.29 \%)$ were women $(n=19)$. Mean age was $M=35.03$ years $(S D=7.94)$ and mean body-mass-index $(\mathrm{BMI})$ was $M=26.67 \mathrm{~kg} / \mathrm{m}^{2}$ $(S D=5.44)$. Participants either had an amaurosis $(n=10)$ or had a maximum sight of $30 \%$ with visual aid. Four participants were on medication for hypertension. 


\section{Heart rate recording}

Measurement of heart rate was performed at rest with the heart rate monitor Polar RS800CX (Polar Electro Oy, Kempele, Finland) for $10 \mathrm{~min}$. For analysis and calculation of HRV the software Kubios HRV 2.0 (Tarvainen et al. 2009) was used. Only the last five minutes of the collected data were used for calculation of HRV to ensure that data reflected resting conditions. Inter-beat interval series were corrected for artifacts using the default settings of the program. Trend components were removed with the smoothness priors detrending method $(\lambda=500)$. We chose the root mean square of successive differences (RMSSD) as a measure of HRV. This parameter is recommended as a measure of vagal-cardiac outflow because of its robustness, e.g. against changes in breathing rate (Task Force of The European Society of Cardiology and The North American Society of Pacing and Electrophysiology 1996, Penttilä et al. 2001). As an additional index of parasympathetically mediated HRV, we performed a spectral analysis (Fast Fourier Transformation) and determined high frequency components $(0.15-0.4 \mathrm{~Hz})$ both as high frequency power $\left(\mathrm{HF} \mathrm{ms}{ }^{2}\right.$ ) and normalized units ( $\mathrm{HF} \mathrm{nu}=\mathrm{HF} \mathrm{ms} \mathrm{m}^{2} /$ (total power $\mathrm{ms}^{2}$ - very low frequency $\left.\mathrm{ms}^{2}\right)$ ). RMSSD and $\mathrm{HF} \mathrm{ms}^{2}$ were log-transformed (ln) because of skewed distribution.

\section{Comprehensive Quality of Life Scale - Intellectual Disability (Com-QOL-ID)}

The Com-QOL-ID (Cummins et al. 1997; German version by Krüger 1998) was specifically developed for individuals with intellectual disabilities. It measures objective and subjective quality of life. The subjective quality of life scale is further divided into importance of and satisfaction with several life domains. We only used the total scores for objective and subjective quality of life in the present study for the sake of brevity and clarity $^{1}$. Internal consistency for objective quality of life is $\alpha=.56$ and $\alpha=.68$ (satisfaction) and $\alpha=.48$ (importance) for subjective quality of life (Townsend-White et al. 2012). In the original version of the Com-QOL-ID, pictures of blocks and faces are used as response options (Figure 1). Due to the visual impairment of our participants all blocks were enlarged and replicated three-dimensionally, so that participants could experience the blocks tactually. Furthermore, faces were modeled with clay, enlarged and painted with easily recognizable colors (Figure 1). The number of response options was determined individually according to the scale's manual (Krüger 1998).

\section{Emotion Regulation Questionnaire (ERQ)}

The ERQ by Gross and John (2003) measures habitual use of emotion regulation strategies, in particular cognitive reappraisal and expressive suppression. Internal consistencies are acceptable in samples without intellectual disabilities (suppression: $\alpha=.74$; reappraisal: $\alpha=.76$; Abler and Kessler 2009). In the present study, the German version of the ERQ by Abler and Kessler (2009) was modified linguistically to simplify sentences for people with intellectual disabilities (Table 1). For each item an example was provided. The number of response options for each participant was adopted from the pre-test of the Com-QOL-ID in order to reduce the level of abstraction and complexity. One item ("I control my emotions by changing the way I think about the situation I'm in.") was assessed as too difficult and, therefore, excluded. Internal consistencies were $\alpha=.77$ (reappraisal) and $\alpha=.52$ (suppression) in the present study. 


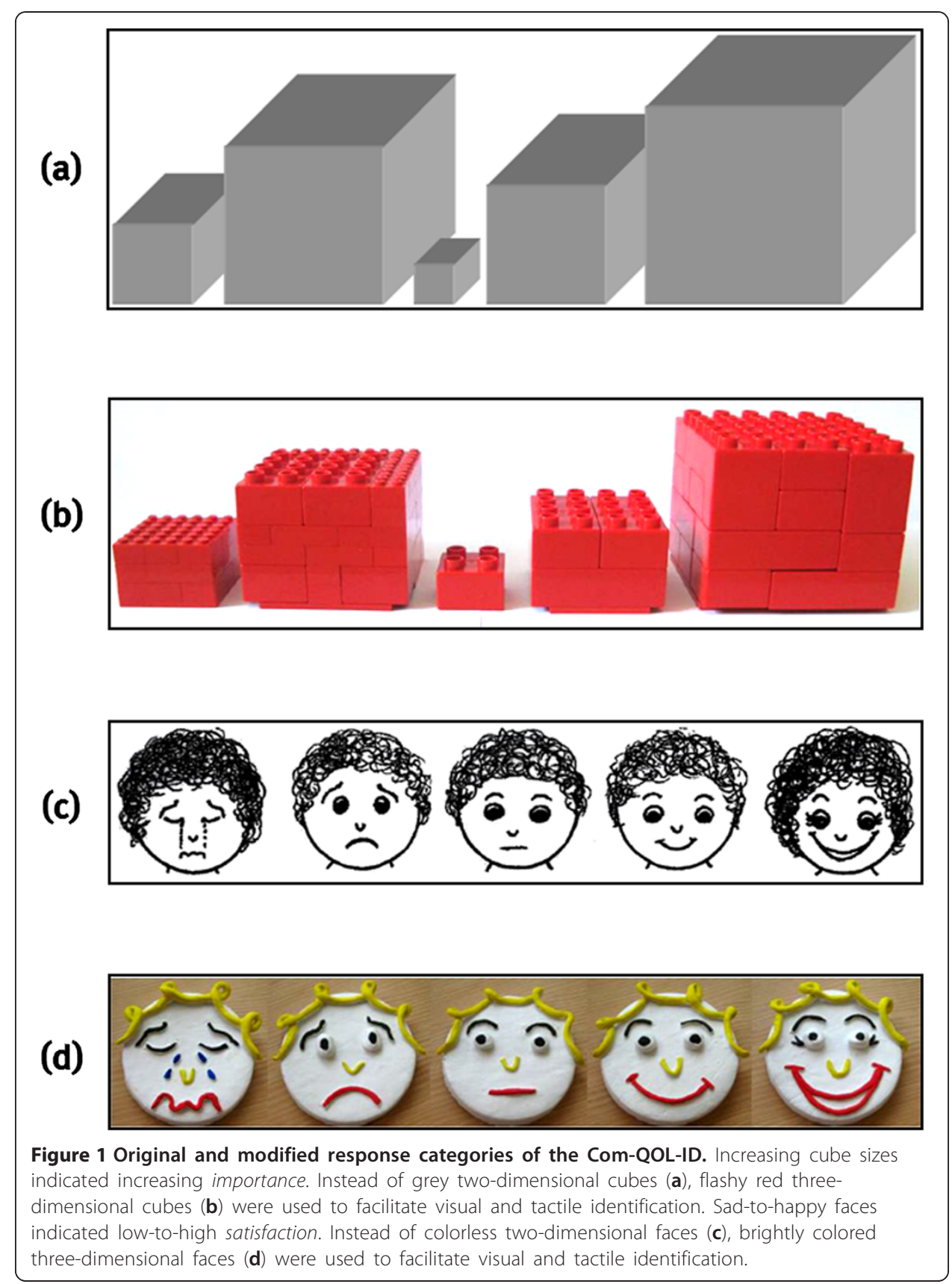

\section{Procedure}

A few days before the testing, participants became acquainted with the investigator. They were informed about the course of action and were familiarized with the instrument for heart rate monitoring. To ensure participants' complete understanding of the study's procedure, all steps were explained in full detail and any remaining questions answered. After a preliminary interview about demographic data, the interview on quality of life and emotion regulation followed. During a $10 \mathrm{~min}$ break, participants were asked to disengage from any negative thoughts and feelings they might have and to calm down and relax. After the break, heart rate was measured for $10 \mathrm{~min}$. The 
Table 1 Original and modified items of the Emotion Regulation Questionnaire

\begin{tabular}{l} 
Original items \\
\hline 1. When I want to feel more \\
positive emotion (such as joy or \\
amusement), I change what I'm \\
thinking about. \\
[Wenn ich mehr positive Gefühle \\
(wie Freude oder Heiterkeit) \\
empfinden möchte, ändere ich, \\
woran ich denke.]
\end{tabular}

2. I keep my emotions to myself.

[lch behalte meine Gefühle für mich.]

3. When I want to feel less negative emotion (such as sadness or anger), I change what I'm thinking about.

Wenn ich weniger negative Gefühle (wie Traurigkeit oder Ärger) empfinden möchte, ändere ich, woran ich denke.]

4. When I am feeling positive emotions, I am careful not to express them.

WWenn ich positive Gefühle empfinde, bemühe ich mich, sie nicht nach außen zu zeigen.]

5. When I'm faced with a stressful situation, I make myself think about situation, I make myself think about it in a way that helps me stay calm. it in a way that helps me stay calm.

[Wenn ich in eine stressige Situation gerate, ändere ich meine Gedanken über die Situation so, dass es mich beruhigt.]

6. I control my emotions by not expressing them.

[lch halte meine Gefühle unter Kontrolle, indem ich sie nicht nach außen zeige.]

7. When I want to feel more positive emotion, I change the way I'm thinking about the situation.

\section{Modified items}

When I want to have more good

feelings like joy or amusement,

think of something nice.

[Wenn ich mehr gute Gefühle, wie Freude oder Heiterkeit empfinden möchte, denke ich an etwas Schöneres.]

I often do not show to others how I feel at the moment.

[Ich zeige den anderen oft nicht, wie ich mich gerade fühle.]

When I want to have less bad feelings like sadness or anger, I think of something nice.

WWenn ich weniger schlechte Gefühle, wie Traurigkeit oder Ärger empfinden möchte, denke ich an etwas Schöneres.]

When I am feeling good, I do not show this to others.

[Wenn ich mich gut fühle, zeige ich das nicht den anderen.]

[Wenn ich in eine stressige Situation gerate, ändere ich meine Gedanken über die Situation so, dass es mich beruhigt.]

When I do not show my feelings, can control them better.

WWenn ich meine Gefühle nicht zeige, habe ich sie besser unter Kontrolle.]

When I want to have more good feelings, I try to think differently about the situation.

WWenn ich mehr gute Gefühle empfinden möchte, versuche ich

\section{Examples}

When I am sad and want to feel better, I think of something nice like eating ice cream in the sun or a happy celebration.

[Wenn ich traurig bin und mich besser fühlen möchte, stelle ich mir etwas Schönes vor, wie Eis essen im Sonnenschein oder ein lustiges Fest.]

When I am in a very good or bad mood, I do not tell others.

[Wenn ich total gut oder total schlecht gelaunt bin, dann sage ich das nicht den anderen.]

When I am sad and I do not want to feel so sad, I think of something nice like eating ice cream in the sun or a happy celebration.

Wenn ich traurig bin und mich nicht so traurig fühlen möchte, stelle ich mir auch etwas Schönes vor, wie Eis essen im Sonnenschein oder ein lustiges Fest.]

When I arrive at work in the morning feeling great, I do not show this and I am rather quiet or talk about something else.

[Wenn ich morgens total gut gelaunt zur Arbeit komme, dann zeige ich das nicht und bin eher ganz still oder rede über etwas anderes.]

When I get home late from work and still have a doctor's appointment or I am on duty in my group, I think that, although today is stressful, I will have my peace tomorrow.

[Wenn ich spät von der Werkstatt komme und noch einen Arzttermin oder Dienst in der Gruppe habe, dann denke ich daran, dass es heute zwar stressig ist, aber dafür habe ich morgen wieder meine Ruhe.]

When I feel my anger rising, I do not show this to the others and as a result I am not getting so angry. Then, my anger wears off.

[Wenn Ärger langsam in mir hochsteigt, dann zeige ich das nicht den anderen und dann werde ich auch nicht so wütend. Meine Wut vergeht dann wieder.]

When I made a mistake at work and I am angry about it and want to feel better, I remind myself that everyone makes a mistake sometimes and it is not so bad.

Wenn ich einen Fehler in der Werkstatt gemacht habe, darüber 
Table 1 Original and modified items of the Emotion Regulation Questionnaire (Continued)

\begin{tabular}{ll}
\hline über die Situation anders zu & anders über die Situation zu \\
denken.] & denken.]
\end{tabular}
denken.]

8. I control my emotions by changing the way I think about the situation I'm in.

[Ich halte meine Gefühle unter Kontrolle, indem ich über meine aktuelle Situation anders nachdenke.]

9. When I am feeling negative emotions, I make sure not to express them.

[Wenn ich negative Gefühle empfinde, sorge ich dafür, sie nicht nach außen zu zeigen.]

10. When I want to feel less negative emotion, I change the way I'm thinking about the situation.

[Wenn ich weniger negative Gefühle empfinden möchte, versuche ich über die Situation anders zu denken.]

\begin{abstract}
When I feel bad, I do not show this When I arrive at work in the to others. morning in a bad mood because I may have slept badly, I do not show this to others and I am rather quiet or talk about something else.

[Wenn ich mich schlecht fühle, zeige ich das nicht den anderen.]

[Wenn ich morgens schlecht gelaunt zur Arbeit komme, weil ich vielleicht schlecht geschlafen habe, dann zeige ich das nicht und bin eher ganz still oder rede über etwas anderes.]
\end{abstract}

When I want to have less bad feelings, I try to think differently about the situation.

When I made a mistake at work and I am angry about it and do not want to feel so bad, I remind myself that everyone makes a mistake from time to time.

[Wenn ich weniger schlechte Gefühle empfinden möchte, versuche ich anders über die Situation zu denken.]
[Wenn ich einen Fehler in der Werkstatt gemacht habe, darüber verärgert bin und mich nicht so schlecht fühlen möchte, dann denke ich daran, dass jeder mal einen Fehler macht.]

Notes. Original items are from Gross and John (2003) and Abler and Kessler (2009), respectively. The German wording is displayed in parentheses. Item \#8 deemed too difficult and, therefore, was excluded. Participants were provided with an example situation for each item.

session ended with a qualitative follow-up interview on well-being during the heart rate recording, and the participants' debriefing.

\section{Data analysis}

Three participants were excluded because of missing data leaving $n=32$ in the final sample. All variables used in the subsequent regression analyses were $z$-standardized. We first analyzed the association between emotion regulation strategies (i.e. reappraisal, suppression, and the interaction reappraisal $\times$ suppression) and quality of life. The variable with the highest $\beta$ was chosen as mediating variable in subsequent mediation analyses (i.e., whether emotion regulation strategies mediated the effect of HRV on quality of life). In addition to regression analyses, the Goodman test (Goodman 1960) was used to test mediation effects. All statistical analyses were tested one-tailed because of our directed hypotheses.

\section{Results}

Descriptive data of and correlations between all variables are reported in Table 2. High frequency power was highly correlated with RMSSD and its use yielded similar results in the subsequent analyses. Therefore, only results for RMSSD are reported. 
Table 2 Descriptive statistics and correlations between study variables

\begin{tabular}{|c|c|c|c|c|c|c|c|c|c|c|c|}
\hline & $n$ & $M$ & $S D$ & Range & 1. & 2. & 3. & 4. & 5. & 6. & 7. \\
\hline \multicolumn{12}{|c|}{ Emotion Regulation Questionnaire } \\
\hline 1. Reappraisal & 32 & 3.40 & 0.79 & $1.80-4.60$ & - & -.13 & $.32^{*}$ & $.40^{*}$ & .13 & .13 & .12 \\
\hline 2. Suppression & 32 & 2.68 & 0.72 & $1.00-4.00$ & -.13 & - & .20 & .05 & -.03 & -.11 & -.03 \\
\hline \multicolumn{12}{|c|}{ Comprehensive Quality of Life Scale } \\
\hline 3. Objective quality of life & 34 & 3.30 & 0.37 & $2.67-4.04$ & $.32^{*}$ & .20 & - & $.60^{* * *}$ & $.35^{*}$ & $.33^{*}$ & $.29^{*}$ \\
\hline 4. Subjective quality of life & 34 & 14.15 & 5.73 & $1.14-23.57$ & $.40^{*}$ & .05 & $.60^{* * *}$ & - & .08 & .08 & .08 \\
\hline \multicolumn{12}{|l|}{ Heart rate variability } \\
\hline 5. RMSSD & 34 & 35.48 & 22.02 & $9.30-81.80$ & .13 & -.03 & $.35^{*}$ & .08 & - & $.96^{* * *}$ & $.70^{* * *}$ \\
\hline $\begin{array}{l}\text { 6. High frequency power } \\
\left(m s^{2}\right)\end{array}$ & 34 & 607.77 & 806.05 & $14.00-2982.00$ & .13 & -.11 & $.33^{*}$ & .08 & $.96^{* * *}$ & - & $.66^{* * *}$ \\
\hline $\begin{array}{l}\text { 7. High frequency power } \\
\text { (n.u.) }\end{array}$ & 34 & 45.62 & 17.57 & $10.60-79.60$ & .12 & -.03 & $.29^{*}$ & .08 & $.70^{* * *}$ & $.66^{* * *}$ & - \\
\hline
\end{tabular}

Notes. RMSSD $=$ Root mean square of successive differences. Note that descriptive statistics for RMSSD and high frequency power $\left(\mathrm{ms}^{2}\right)$ are displayed before log-transformation. ${ }^{*} p<.05$ (one-tailed), ${ }^{* * *} \mathrm{p}<.001$ (one-tailed).

\section{Emotion regulation and quality of life}

Reappraisal and suppression were not correlated $(r=-.13, n s)$ while a high positive correlation was found between objective and subjective quality of life $(r=.60, p<.001)$. The models of emotion regulation predicting quality of life were significant for both objective quality of life $\left(F_{(3,28)}=3.29, p=.02\right.$, adj. $\left.R^{2}=.18\right)$ and subjective quality of life $\left(F_{(3,28)}=4.23, p=.01\right.$, adj. $\left.R^{2}=.24\right)$. Reappraisal, but not suppression, predicted both objective and subjective quality of life (Table 3 ). The interaction of reappraisal $\times$ suppression was also a significant predictor of both objective and subjective quality of life (Table 3). To examine the nature of this interaction, we computed simple slopes for the regressions of reappraisal on quality of life for individuals with low suppression (one standard deviation below the mean) and those with high suppression (one standard deviation above the mean; Aiken and West 1991). Reappraisal positively predicted objective quality of life only when suppression was high $\left(\beta=.65, t_{(28)}=2.88, p=.004\right)$, but not when suppression was low $\left(\beta=-.03, t_{(28)}=-.13, n s\right)$. Similarly, reappraisal positively predicted subjective quality of life only when suppression was high $\left(\beta=.77, t_{(28)}=3.55\right.$, $p<.001)$, but not when suppression was low $\left(\beta=-.07, t_{(28)}=-.26\right.$, $n s$, Figure 2$)$.

Table 3 Emotion regulation strategies predicting quality of life

\begin{tabular}{llll}
\hline & $\boldsymbol{\beta}$ & $\boldsymbol{t}$ & $\boldsymbol{p}$ \\
\hline Objective quality of life & & & \\
Reappraisal & .31 & 1.85 & .04 \\
Suppression & -.02 & -.09 & .46 \\
Reappraisal $\times$ suppression & .41 & 1.90 & .03 \\
Subjective quality of life & & & \\
Reappraisal & .35 & 2.19 & .02 \\
Suppression & -.23 & -1.10 & .14 \\
Reappraisal $\times$ suppression & .50 & 2.42 & .01 \\
\hline
\end{tabular}




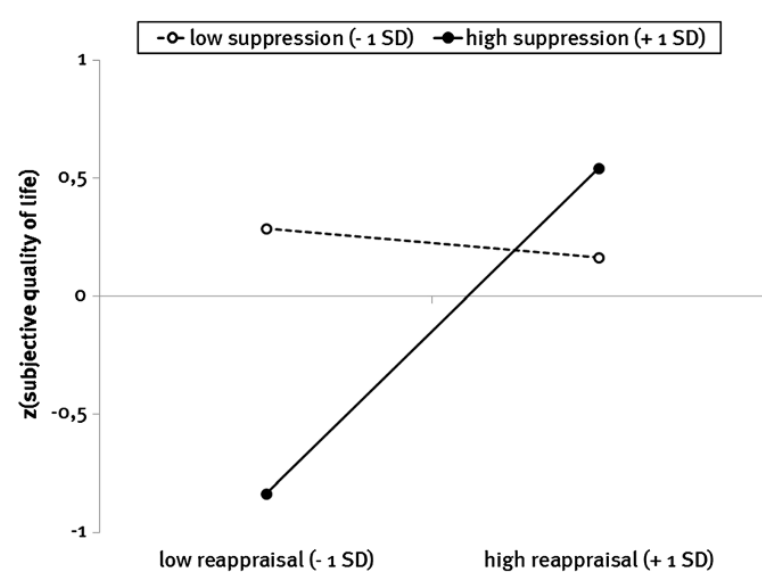

Figure 2 Predicted subjective quality of life as a function of reappraisal and suppression (all variables $z$-standardized). High and low values represent plus or minus one standard deviation from the respective mean.

\section{Mediation analyses}

\section{Objective quality of life}

HRV significantly predicted objective quality of life $\left(F_{(1,32)}=4.45, p=.02\right.$, adj. $\left.R^{2}=.10\right)$ and emotion regulation $\left(F_{(1,30)}=3.36, p=.04\right.$, adj. $\left.R^{2}=.10\right)$. Beta-weights are depicted in Table 4. The overall model including both HRV and emotion regulation as predictors was also significant $\left(F_{(2,29)}=4.16, p=.01\right.$, adj. $\left.R^{2}=.17\right)$. While emotion regulation still was a significant predictor in this model, the influence of HRV was only marginally significant (Table 4). Testing of the mediating effect of emotion regulation between HRV and objective quality of life was marginally significant (Goodman $z=1.42, p=.08$ ).

\section{Subjective quality of life}

HRV was not a significant predictor of subjective quality of life $\left(F_{(1,32)}=.18, p=.34\right.$, adj. $\left.R^{2}=-.03\right)$. The overall model including both HRV and emotion regulation as predictors was marginally significant $\left(F_{(2,29)}=2.24, p=.06\right.$, adj. $\left.R^{2}=.07\right)$. While emotion

Table 4 Mediation testing steps for quality of life

\begin{tabular}{llll}
\hline & $\boldsymbol{\beta}$ & $\boldsymbol{t}$ & $\boldsymbol{p}$ \\
\hline Step 1 & .35 & & .02 \\
HRV to objective quality of life & .08 & .11 & .34 \\
HRV to subjective quality of life & & & \\
Step 2 & .32 & 1.83 & .04 \\
HRV to emotion regulation & & & \\
Step 3 & & & .08 \\
Predicting objective quality of life & .26 & 1.48 & .04 \\
HRV & .33 & 1.88 & .45 \\
$\quad$ Emotion regulation & & & .03 \\
Predicting subjective quality of life & .02 & .13 & 1.96 \\
$\quad$ HRV & .36 & & \\
Emotion regulation &
\end{tabular}

Note. HRV = Heart rate variability (log-transformed root mean square of successive differences); Emotion regulation $=$ interactive term of reappraisal $\times$ suppression. 
regulation still was a significant predictor in this model, the influence of HRV was again not significant (Table 4). Testing of the mediating effect of emotion regulation between HRV and subjective quality of life was marginally significant (Goodman $z=$ $1.45, p=.07)$.

\section{Discussion}

In the current study, we assessed quality of life, emotion regulation strategies and HRV in a sample of individuals with intellectual disabilities and concomitant impaired vision. We modified existing questionnaires by using three-dimensional response categories to overcome restricted visual information processing in our participants. To our knowledge, this is the first study that (1) used such an assessment technique and (2) investigated emotion regulation and related it to quality of life and cardiac autonomic regulation in individuals with intellectual disabilities.

We found that higher scores of reappraisal were positively associated with subjective and objective quality of life, replicating prior findings in individuals without intellectual disabilities (Geisler et al. 2010). The interaction between reappraisal and suppression was also associated with high quality of life. The positive relationship between reappraisal and quality life was particularly pronounced when suppression was high or, vice versa, high suppression with concomitant low reappraisal was associated with lower quality of life (Figure 2). Hence, the use of reappraisal may compensate for the use of suppression and, therefore, contribute to higher quality of life. This finding is also consistent with a recent study in a sample of community residents, which found that the relationship between adaptive emotion regulation strategies and psychopathology is moderated by the level of maladaptive strategies. Specifically, the negative association between adaptive strategies and psychopathology was stronger at high levels of maladaptive strategies (Aldao and Nolen-Hoeksema 2012).

The combined use of emotion regulation strategies was also related to higher HRV. This finding is in accordance with HRV representing flexible adaptations of physiological processes, but also more adaptive emotion regulation (Appelhans and Luecken 2006, Thayer and Lane 2009). As a result, the current study further supports the use of physiological indices to evaluate affective conditions in people with intellectual disabilities (Vos et al. 2012).

There was a strong association between HRV and objective quality of life. As expected, this link was (partially) mediated via the flexible use of emotion regulation strategies. No evidence was found for an association between HRV and subjective quality of life. However, mediation analysis showed a trend toward mediation of HRV on subjective quality of life also via the combined use of emotion regulation strategies. Thus, subjective quality of life and HRV appear to be indirectly associated (refer to Zhao et al. 2010 for rationale of exploring mediation effects in the absence of direct effects). The strong association between HRV and objective quality of life may be explained by the inclusion of items about physical health in this subscale ${ }^{2}$, a factor known to influence HRV (Thayer et al. 2010). Beyond this relationship, however, emotion regulation strategies partially mediated the relationship between HRV and quality of life, which is largely consistent with the results from the study by Geisler et al. (2010). 
Several limitations of this study have to be mentioned. Firstly, the medium sample size may restrict generalization of our results. Secondly, there was no control group and, therefore, it cannot be evaluated if participants in our study had generally lower HRV than individuals without intellectual disabilities. However, it appears that HRV was comparable to individuals without intellectual disabilities (Sinnreich et al. 1998; Agelink et al. 2001; Nunan et al. 2010; Bertsch et al. 2012). Thirdly, we changed the response modality of the questionnaires from visual to visuo-tactile and modified the items of the ERQ. As a result, psychometric properties may have been affected. Yet, internal consistency was acceptable, at least for the reappraisal subscale. These caveats notwithstanding, we could demonstrate associations between emotion regulation, HRV and quality of life in a sample heterogeneous in age, gender, body mass and visual impairment which favors external validity of our results.

\section{Conclusions}

Our results support positive relationships between HRV, emotion regulation, and quality of life and the mediating role of emotion regulation between these variables. Importantly, we could demonstrate that these associations also extend to people with intellectual disabilities and concomitant impaired vision. The assessment of quality of life is complex in individuals with intellectual disabilities and requires more sophisticated approaches than simple interview, e.g. multi-modal methods (McVilly et al. 2008). Future studies may also make use of more recently developed quality of life measures, e.g. the Integral Quality of Life Scale (Verdugo et al. 2011). In addition, we presented new approaches for measuring emotion regulation and quality of life, namely questionnaires with visuo-tactile response modalities and assessment of HRV. The results may encourage further studies on quality of life that apply those techniques in individuals with intellectual disabilities. When both emotion regulation problems are present and HRV is low, intervention programs may be considered which have been shown to be beneficial in people without intellectual disabilities, e.g. HRV-biofeedback (Wheat and Larkin 2010). Such interventions may boost emotion regulation abilities and, thus, may indirectly enhance quality of life in people with intellectual disabilities.

\section{Endnotes}

${ }^{1}$ Note that we used the combined score for subjective quality of life (importance $x$ satisfaction) as it is suggested in the questionnaire's manual. Although this procedure has been criticized, it has been found that the combined score usually behaves like the satisfaction score alone and thus does not adversely affect outcomes (Cummins 2002). In the present study, the satisfaction score and the combined score were almost perfectly correlated $(r=.99, p<.001)$. Accordingly, correlations when using the satisfaction score were similar to the combined score.

${ }^{2}$ Indeed, the largest correlation between objective quality of life dimensions and HRV was observed for health (health: $r=.46, p<.01$; emotional well-being: $r=.38, p<.05$; place in community: $r=.34, p<.05$; safety: $r=.26, p<.07$; productivity: $r=.10$, ns; intimacy: $r=-.05$, ns; material well-being: $r=-.16, n s)$. 


\section{Authors' contributions}

KF, SS, CV, and AK conceived and designed the study. KF collected the data. AM and RR performed the statistical analyses. AM and KF wrote the first draft of the manuscript. RR, SS, CV, and AK revised the manuscript for content. All authors read and approved the final manuscript.

\section{Acknowledgments}

AM is supported by a grant of the research training group 1253/2 which is supported by the German Research Foundation (Deutsche Forschungsgemeinschaft, DFG) by federal and Länder funds. This publication was funded by the DFG and the University of Wuerzburg in the funding program Open Access Publishing.

\section{Author details}

'Department of Psychology I, Institute of Psychology, University of Wuerzburg, Marcusstr. 9-11, 97070 Wuerzburg, Germany. ${ }^{2}$ Blindeninstitut, Ohmstr. 7, 97076 Wuerzburg, Germany. ${ }^{3}$ Research Unit INSIDE, Université du Luxembourg, Route de Diekirch - BP2, L-7220 Walferdange, Luxembourg. ${ }^{4}$ Research Group on Health Psychology, University of Leuven, Tiensestraat 102, B-3000 Leuven, Belgium. Institute of Medical Psychology and Behavioural Neurobiology, University of Tübingen, Gartenstr. 29, 72074 Tuebingen, Germany.

\section{Received: 19 November 2012 Accepted: 21 March 2013}

Published: 27 March 2013

\section{References}

Abler, B, \& Kessler, H. (2009). [Emotion Regulation Questionnaire - A German version of the ERQ by Gross and John]. Diagnostica, 55, 144-152.

Agelink, MW, Malessa, R, Baumann, B, Majewski, T, Akila, F, Zeit, T, et al. (2001). Standardized tests of heart rate variability: normal ranges obtained from 309 healthy humans, and effects of age, gender, and heart rate. Clinical Autonomic Research, 11, 99-108.

Aiken, LS, \& West, SG (1991). Multiple regression: Testing and interpreting interactions. Thousand Oaks, CA: Sage.

Aldao, A, \& Mennin, DS. (2012). Paradoxical cardiovascular effects of implementing adaptive emotion regulation strategies in generalized anxiety disorder. Behaviour Research and Therapy, 50, 122-130.

Aldao, A, \& Nolen-Hoeksema, S. (2012). When are adaptive strategies most predictive of psychopathology? Journal of Abnormal Psychology, 121, 276-281.

Appelhans, BM, \& Luecken, L. (2006). Heart rate variability as an index of regulated emotional responding. Review of General Psychology, 10, 229-240.

Baker, BL, Blacher, J, Crnic, KA, \& Edelbrock, C. (2002). Behavior problems and parenting stress in families of three-year -old children with and without developmental delays. American Journal of Mental Retardation, 107, 433-444.

Baurain, C, \& Nader-Grosbois, N. (2012). Socio-emotional regulation in children with intellectual disability and typically developing children in interactive contexts. ALTER - European Journal of Disability Research, 6, 75-93.

Baynard, T, Pitetti, KH, Guerra, M, \& Fernhall, B. (2004). Heart rate variability at rest and during exercise in persons with Down syndrome. Archives of Physical Medicine and Rehabilitation, 85, 1285-1290.

Bertsch, K, Hagemann, D, Naumann, E, Schachinger, H, \& Schulz, A. (2012). Stability of heart rate variability indices reflecting parasympathetic activity. Psychophysiology, 49, 672-682.

Bonanno, GA, Papa, A, Lalande, K, Westphal, M, \& Coifman, K. (2004). The importance of being flexible - the ability to both enhance and suppress emotional expression predicts long-term adjustment. Psychological Science, $15,482-487$.

Chang, Y-W, Lin, J-D, Chen, W-L, Yen, C-F, Loh, C-H, Fang, W-H, et al. (2012). Metabolic syndrome and short-term heart rate variability in adults with intellectual disabilities. Research in Developmental Disabilities, 33, 1701-1707.

Cummins, RA. (1997). Self-rated quality of life scales for people with an intellectual disability: A review. Journal of Applied Research in Intellectual Disabilities, 10, 199-216.

Cummins, RA (2002). Vale ComQol: Caveats to using the Comprehensive Quality of Life Scale. Available at http://www. deakin.edu.au/research/acqol/instruments/comqol-scale.

Cummins, RA, McCabe, MP, Romeo, Y, \& Gullone, E. (1994). The Comprehensive Quality of Life Scale (ComQol): Instrument development and psychometric evaluation on college staff and students. Educational and Psychological Measurement, 54, 372-382.

Cummins, RA, McCabe, MP, Romeo, Y, Reid, S, \& Waters, L. (1997). An initial evaluation of the Comprehensive Quality of Life Scale - Intellectual Disability. International Journal of Disability, Development and Education, 44, 7-19.

Geisler, FCM, Vennewald, N, Kubiak, T, \& Weber, H. (2010). The impact of heart rate variability on subjective well-being is mediated by emotion regulation. Personality and Individual Differences, 49, 723-728.

Goodman, LA. (1960). On the exact variance of products. Journal of the American Statistical Association, 55, 708-713.

Gorbunov, NP. (2004). Changes in the heart rate parameters under the influence of academic school activities in adolescents with mental retardation. Human Physiology, 30, 310-314.

Gross, JJ. (2002). Emotion regulation: affective, cognitive, and social consequences. Psychophysiology, 39, 281-291.

Gross, JJ, \& John, OP. (2003). Individual differences in two emotion regulation processes: implications for affect, relationships, and well-being. Journal of Personality and Social Psychology, 85, 348-362.

Krüger, C (1998). Comprehensive Quality of Life Scale - Intellectual/Cognitive Disability: German version. Hamburg: University of Hamburg.

McClure, KS, Halpern, J, Wolper, PA, \& Donahue, JJ. (2009). Emotion regulation and intellectual disability. Journal on Developmental Disabilities, 15, 38-44.

McLinden, M. (2012). Mediating haptic exploratory strategies in children who have visual impairment and intellectual disabilities. Journal of Intellectual Disability Research, 56, 129-139.

McVilly, KR, Green, AM, Hawthorne, G, Cummins, R, Hobbs, J, \& Wong, S. (2008). Developing a QOL measure: What (and what not) to ask and how (and how not) to ask it. Journal of Intellectual Disability Research, 52, 779. 
Nunan, D, Sandercock, GRH, \& Brodie, DA. (2010). A quantitative systematic review of normal values for short-term heart rate variability in healthy adults. Pacing and Clinical Electrophysiology, 33, 1407-1417.

Penttilä, J, Helminen, A, Jartti, T, Kuusela, T, Huikuri, HV, Tulppo, MP, et al. (2001). Time domain, geometrical and frequency domain analysis of cardiac vagal outflow: effects of various respiratory patterns. Clinical Physiology, $21,365-376$.

Phillips, LH, Saldias, A, McCarrey, A, Henry, JD, Scott, C, Summers, F, et al. (2009). Attentional lapses, emotional regulation and quality of life in multiple sclerosis. British Journal of Clinical Psychology, 48, 101-106.

Segerstrom, SC, \& Solberg Nes, L. (2007). Heart rate variability reflects self-regulatory strength, effort, and fatigue. Psychological Science, 18, 275-281.

Sinnreich, R, Kark, JD, Friedlander, Y, Sapoznikov, D, \& Luria, MH. (1998). Five minute recordings of heart rate variability for population studies: repeatability and age-sex characteristics. Heart, 80, 156-162.

Smith, TW, Cribbet, MR, Nealey-Moore, JB, Uchino, BN, Williams, PG, MacKenzie, J, et al. (2011). Matters of the variable heart: respiratory sinus arrhythmia response to marital interaction and associations with marital quality. Journal of Personality and Social Psychology, 100, 103-119.

Tarvainen, MP, Niskanen, J-P, Lipponen, JA, Ranta-aho, PO, \& Karjalainen, PA (2009). Kubios HRV - A software for advanced heart rate variability analysis. In J Vander Sloten, P Verdonck, M Nyssen, J Haueisen (Eds.), 4th European Conference of the International Federation for Medical and Biological Engineering (pp. 1022-1025). Antwerp, Belgium: Springer.

Task Force of The European Society of Cardiology and The North American Society of Pacing and Electrophysiology. (1996). Heart rate variability - Standards of measurement, physiological interpretation, and clinical use. European Heart Journal, 17, 354-381.

Thayer, JF, Åhs, F, Fredrikson, M, Sollers, JJ, 3rd, \& Wager, TD. (2012). A meta-analysis of heart rate variability and neuroimaging studies: Implications for heart rate variability as a marker of stress and health. Neuroscience and Biobehavioral Reviews, 36, 747-756.

Thayer, JF, \& Lane, RD. (2000). A model of neurovisceral integration in emotion regulation and dysregulation. Journal of Affective Disorders, 61, 201-216.

Thayer, JF, \& Lane, RD. (2009). Claude Bernard and the heart-brain connection: Further elaboration of a model of neurovisceral integration. Neuroscience and Biobehavioral Reviews, 33, 81-88.

Thayer, JF, Yamamoto, SS, \& Brosschot, JF. (2010). The relationship of autonomic imbalance, heart rate variability and cardiovascular disease risk factors. International Journal of Cardiology, 141, 122-131.

Townsend-White, C, Pham, AN, \& Vassos, MV. (2012). A systematic review of quality of life measures for people with intellectual disabilities and challenging behaviours. Journal of Intellectual Disability Research, 56, 270-284.

United Nations (2006). Convention on the rights of persons with disabilities and optional protocol. New York: United Nations.

Verdugo, MA, Gómez, LE, Arias, B, \& Schalock, RL (2011). The Integral Quality of Life Scale: development, validation, and use. In R. Kober (Ed.), Enhancing the Quality of Life of People with Intellectual Disabilities (pp. 47-60). Dordrecht: Springer.

Vögele, C, Sorg, S, Studtmann, M, \& Weber, H. (2010). Cardiac autonomic regulation and anger coping in adolescents. Biological Psychology, 85, 465-471.

Vos, P, De Cock, P, Munde, V, Petry, K, Van den Noortgate, W, \& Maes, B. (2012). The tell-tale: What do heart rate, skin temperature and skin conductance reveal about emotions of people with severe and profound intellectual disabilities? Research in Developmental Disabilities, 33, 1117-1127.

Webb, TL, Miles, E, \& Sheeran, P. (2012). Dealing with feeling: a meta-analysis of the effectiveness of strategies derived from the process model of emotion regulation. Psychological Bulletin, 138, 775-808.

Wheat, AL, \& Larkin, KT. (2010). Biofeedback of heart rate variability and related physiology: A critical review. Applied Psychophysiology and Biofeedback, 35, 229-242.

Wilson, BJ. (1999). Entry behavior and emotion regulation abilities of developmentally delayed boys. Developmental Psychology, 35, 214-222

World Medical Association (2008). Declaration of Helsinki - Ethical Principles for Medical Research Involving Human Subjects. Seoul: 59th World Medical Association General Assembly.

Zhao, X, Lynch, JG, Jr, \& Chen, Q. (2010). Reconsidering Baron and Kenny: myths and truths about mediation analysis. Journal of Consumer Research, 37, 197-206.

doi:10.1186/2211-1522-3-1

Cite this article as: Meule et al: Quality of life, emotion regulation, and heart rate variability in individuals with intellectual disabilities and concomitant impaired vision. Psychology of Well-Being: Theory, Research and Practice 2013 3:1.

\section{Submit your manuscript to a SpringerOpen ${ }^{\circ}$ journal and benefit from:}

- Convenient online submission

Rigorous peer review

- Immediate publication on acceptance

- Open access: articles freely available online

- High visibility within the field

- Retaining the copyright to your article

Submit your next manuscript at $>$ springeropen.com 